\title{
Laparoscopic assisted vaginal hysterectomy: an experience at a Fortis Escorts hospital
}

\author{
Neelu Rajput ${ }^{1 *}$, Sahab Singh Yadav ${ }^{2}$, Pratibha Narwade ${ }^{1}$
}

\begin{abstract}
${ }^{1}$ Department of Obstetrics and Gynecology, Fortis Escorts Hospital, Faridabad, Haryana, India
${ }^{2}$ Department of Surgery, Bundelkhand Medical College, Sagar, Madhya Pradesh, India
\end{abstract}

Received: 28 June 2020

Accepted: 10 August 2020

*Correspondence:
Dr. Neelu Rajput,
E-mail: blessingall1989@gmail.com

Copyright: (c) the author(s), publisher and licensee Medip Academy. This is an open-access article distributed under the terms of the Creative Commons Attribution Non-Commercial License, which permits unrestricted non-commercial use, distribution, and reproduction in any medium, provided the original work is properly cited.

\begin{abstract}
Background: The objective of this study was to evaluate the laparoscopic assisted vaginal hysterectomy (LAVH) in terms of demographic data of patients, indications, uterine size, intraoperative and postoperative complications, amount of blood loss, operative time and duration of hospital stay.

Methods: A retrospective study was conducted on 160 cases, who underwent laparoscopic assisted vaginal hysterectomy in the period between October 2018 to November 2019 at the Fortis Escorts Hospital, Faridabad, Haryana, India.

Results: Majority of patients (58.75\%) belongs to age group between 40-50 year. Only 30.62\% cases had a history of one previous abdomino-pelvic surgery. Majority of cases $(52.5 \%)$ in the study group had uterine size between 6-12 weeks. Most common indication of hysterectomy in this study was fibroid uterus which account for $49.37 \%$ of cases followed by dysfunctional uterine bleeding (16.87\%) cases. Mean time of surgery in this study was $114.4 \pm 0.59$ min and average blood loss was $135.62 \pm 47.63 \mathrm{ml}$. The mean weight of uterus was $243.75 \pm 82.94 \mathrm{gm}$. $5 \%$ cases had major intraoperative complications while minor postoperative complications were seen in $16.87 \%$ cases. Bladder injury was seen in $1.25 \%$. Major haemorrhage occur in $1.25 \%$. In this study conversion to laparotomy rate was $1.25 \%$. Only one case of ureteric injury and one case of bowel injury was noted. Among minor complications fever $(6.25 \%)$ and urinary tract infection (5.62\%) were mainly seen. Mean duration of hospital stay was $2.82 \pm 1.17$ days.

Conclusions: LAVH enables the surgeon to convert most of the abdominal hysterectomies into vaginal ones and hence decreases postoperative pain, decreases complications, lesser duration of hospital stay and rapid return to normal activity.
\end{abstract}

Keywords: Hysterectomy, Laparoscopic assisted vaginal hysterectomy, Haemmorrhage

\section{INTRODUCTION}

Hysterectomy is the most commonly performed major gynaecological surgical procedure. Benign diseases are responsible for more than $70 \%$ indications for hysterectomy and include menstrual disorders, myomas, pelvic pain, and uterine prolapsed. ${ }^{1}$ Hysterectomy can be performed via 3 routes: open abdominal, vaginal and laparoscopic, but yet there are controversies regarding the optimum route for the procedure. ${ }^{2}$
In 1989, first total laparoscopic hysterectomy (TLH) was performed and published by Reich et al. ${ }^{3}$

The advantages of laparoscopic hysterectomy over abdominal hysterectomy have been reported to be less postoperative pain, shorter hospital stay and more rapid return to normal activities and work. . $^{3,4}$

Laparoscopically assisted vaginal hysterectomy (LAVH) was introduced to overcome the technical difficulties of 
vaginal hysterectomy in case of large uterine size, fixation of the uterus by adhesions, previous pelvic surgery, endometriosis, restricted uterine mobility and adnexal pathology. ${ }^{5,6}$ In addition, it allows one to combine this surgery with other indicated laparoscopic procedures like appendicectomy, cholecystectomy, herniorrhaphy etc. Also, the gynaecologist is able to examine the pelvis thoroughly after completion of surgery to ensure complete haemostasis.

The main aim of laparoscopically assisted vaginal hysterectomy (LAVH) is to enable the surgeon to overcome as many as possible from these contraindications, and hence converting most of the abdominal hysterectomies into vaginal ones.

\section{METHODS}

This is a retrospective observational study of 160 cases, who underwent laparoscopic assisted vaginal hysterectomy in the period between October 2018 to November 2019 at the Fortis Escorts Hospital, Faridabad, Haryana, India.

\section{Inclusion criteria}

In this study, authors included all patients who required hysterectomy for benign conditions.

\section{Exclusion criteria}

In this exclusion criteria, patients with lesions which were either proven or suspicious to be malignant and patients who are candidate for vaginal hysterectomy i.e., having uterine prolapsed.

The LAVH procedure, with its advantages and possible complications, was explained to the patient in the office before deciding on surgery. Detailed demographic details were recorded.
Under general anesthesia, pneumoperitoneum was established. A $10 \mathrm{~mm}$ laparoscope with a Storz endovision camera was inserted in a sub umbilical position. The secondary $5-\mathrm{mm}$ punctures were made, one suprapubic and the other two in both iliac fossae or in both hypochondria regions if the uterus is more than 12 weeks size.

Initial careful inspection of abdomen and pelvis done. If there were adhesions, lysis was done. Round ligaments were coagulated, then cut. Similarly, infundibulopelvic and broad ligaments also coagulated and cut. Vesicouterine peritoneum was dissected and the bladder was displaced inferiorly. Using unipolar hook/scissors, posterior fornix was entered. Anterior fornix was routinely opened vaginally. Bilateral uterine arteries were routinely dealt via vaginal route. Remainder of the surgery was completed vaginally and vaginal cuff closed by interrupted vicryl number 1 sutures. After closing the vaginal cuff, a pneumoperitoneum was recreated to confirm hemostasis. The patients were discharge after 4872 hours. Follow-up visit done after one and six weeks of surgery.

\section{Statistical analysis}

Statistical analysis was done through Microsoft excel. Descriptive analysis done in which for continuous variables, mean and standard deviation (SD) were calculated and for categorical variables, percentages were calculated.

\section{RESULTS}

Table 1 shows majority of patients $(58.75 \%)$ belongs to age group between 40-50 year. Out of 160 cases, only 7 cases $(4.37 \%)$ were nulliparous while $95.63 \%$ cases were parous and majority of cases $(54.37 \%)$ had no history of previous surgery. And $30.62 \%$ cases had a history of one previous abdomino-pelvic surgery.

Table 1: Demography.

\begin{tabular}{|llllllllll|}
\hline Age & $\begin{array}{l}\text { No. of cases } \\
\text { N=160 }\end{array}$ & $\%$ & Parity & $\begin{array}{l}\text { No. of cases } \\
\text { N=160 }\end{array}$ & $\%$ & $\begin{array}{l}\text { H/o of previous } \\
\text { surgery }\end{array}$ & \multicolumn{2}{l|}{$\begin{array}{l}\text { No. of cases } \\
\text { N=160 }\end{array}$} & $\%$ \\
\hline $\mathbf{3 0 - 4 0}$ & 36 & 22.5 & Null & 7 & 4.37 & 0 & 87 & 54.37 \\
\hline $\mathbf{4 0 - 5 0}$ & 94 & 58.75 & Para-1 & 32 & 20.0 & 1 & 49 & 30.62 \\
\hline $\mathbf{5 0 - 6 0}$ & 26 & 16.25 & Para-2 & 50 & 31.25 & 2 & 16 & 10.0 \\
\hline$>\mathbf{6 0}$ & 4 & 2.5 & $>$ para-2 & 71 & 44.37 & $>2$ & 8 & 5 \\
\hline
\end{tabular}

Table 2: Size of the uterus and hysterectomy.

\begin{tabular}{|lll|}
\hline Size of uterus & No. of cases $(\mathbf{N}=160)$ & $\%$ \\
\hline Normal & 8 & 5 \\
\hline Bulky (up to 6 weeks) & 22 & 13.75 \\
\hline 6-12 weeks & 84 & 52.5 \\
\hline $\mathbf{1 2 - 1 6}$ weeks & 34 & 21.25 \\
\hline$>16$ weeks & 12 & 7.5 \\
\hline
\end{tabular}


Table 3: Indications of hysterectomy.

\begin{tabular}{|lll|}
\hline Indications & $\begin{array}{l}\text { No. of cases } \\
(\mathbf{N}=160)\end{array}$ & $\%$ \\
\hline Fibroid & 79 & 49.37 \\
\hline $\begin{array}{l}\text { Dysfunctional uterine } \\
\text { bleeding }\end{array}$ & 27 & 16.87 \\
\hline Adenomyosis & 15 & 9.37 \\
\hline Postmenopausal bleeding & 11 & 6.87 \\
\hline Endometriosis & 10 & 6.25 \\
\hline Ovarian mass & 5 & 3.12 \\
\hline Cervical dysplasia & 5 & 3.12 \\
\hline Tuboovarian mass & 3 & 1.87 \\
\hline Prolapse & 3 & 1.87 \\
\hline Chronic pelvic pain & 2 & 1.25 \\
\hline
\end{tabular}

Table 2 shows majority of cases $(52.5 \%)$ in the study group had uterine size of 6-12 weeks. Only $7.5 \%$ cases were beyond 16 weeks of uterine size. Table 3 shows most common indication of hysterectomy in this study was fibroid uterus which account for $49.37 \%$ of cases followed by dysfunctional uterine bleeding (16.87\%) cases. Adenomyosis account for $9.37 \%$ of cases, postmenopausal bleeding $(6.87 \%)$ cases and endometriosis $(6.25 \%)$ cases. No malignant cases were operated by laparoscopy in this study.

Table 4 shows oophorectomy done in $51.25 \%$ cases, pelvic floor repair in $31.87 \%$ cases, and adhesiolysis in $26.25 \%$ cases. Appendicectomy done in 5\% cases, cholecystectomy and mesh hernioplasty done in $3.12 \%$ cases.

Table 4: Concomitant surgeries.

\begin{tabular}{|lll|}
\hline Concomitant surgeries & No. of cases & $\%$ \\
\hline Oophorectomy & 82 & 51.25 \\
\hline Pelvic floor repair & 51 & 31.87 \\
\hline Adhesiolysis & 42 & 26.25 \\
\hline Appendicectomy & 8 & 5 \\
\hline Cholecystectomy & 5 & 3.12 \\
\hline Herniorrhaphy & 5 & 3.12 \\
\hline
\end{tabular}

Table 5: Intraoperative events.

\begin{tabular}{|llllll|}
\hline Duration of surgery & No. of cases $(\mathbf{N}=\mathbf{1 6 0})$ & $\%$ & Amount of blood loss & No. of cases $(\mathbf{N}=\mathbf{1 6 0})$ & $\%$ \\
\hline$<\mathbf{1}$ hour & 65 & 40.62 & $<100 \mathrm{ml}$ & 26 & 16.25 \\
\hline $\mathbf{1 - 2}$ hours & 89 & 55.62 & $100-150 \mathrm{ml}$ & 71 & 44.37 \\
\hline $\mathbf{2 - 3}$ hours & 4 & 2.5 & $150-200 \mathrm{ml}$ & 53 & 33.12 \\
\hline$>\mathbf{3}$ hours & 2 & 1.25 & $>200 \mathrm{ml}$ & 10 & 6.25 \\
\hline Mean time & $114.4 \pm 0.59 \mathrm{~min}$ & & Average blood loss & $135.62 \pm 47.63 \mathrm{ml}$ \\
\hline
\end{tabular}

Table 6: Weight of uterus.

\begin{tabular}{|c|c|c|}
\hline Weight of uterus & $\begin{array}{l}\text { No. of cases } \\
(\mathrm{N}=160)\end{array}$ & $\%$ \\
\hline$<100$ gm & 5 & 3.12 \\
\hline $100-200$ gm & 36 & 22.5 \\
\hline 200-300 gm & 92 & 57.5 \\
\hline $300-400$ gm & 18 & 11.25 \\
\hline$>400 \mathrm{gm}$ & 9 & 5.62 \\
\hline Mean weight of uterus & $243.75 \pm 82.94$ & \\
\hline
\end{tabular}

Table 5 shows mean time of surgery in this study was $114.4 \pm 0.59 \mathrm{~min}$ and average blood loss was $135.62 \pm 47.63 \mathrm{ml}$.

Table 6 shows the mean weight of uterus was $243.75 \pm 82.94$ gm. $5.6 \%$ cases had uterus weight $>400$ gm.

Table 7 shows 35 cases $(21.8 \%)$ had complication perioperatively. $5 \%$ cases had major intraoperative complications while minor postoperative complications were seen in $16.87 \%$ cases. Bladder injury noted in 2 cases $(1.25 \%)$. Major haemorrhage seen in 2 cases
$(1.25 \%)$. In this study conversion to laparotomy rate was $1.25 \%$.

Table 7: Operative complications.

\begin{tabular}{|lll|}
\hline Complications & $\begin{array}{l}\text { No. of cases } \\
(\mathrm{N}=160)\end{array}$ & $\%$ \\
\hline Major & & \\
\hline Bladder injury & 2 & 1.25 \\
\hline Haemorrhage (major vessel) & 2 & 1.25 \\
\hline Conversion to laparotomy & 2 & 1.25 \\
\hline Ureter injury & 1 & 0.62 \\
\hline Bowel injury & 1 & 0.62 \\
\hline Deep vein thrombosis & 0 & 0 \\
\hline $\begin{array}{l}\text { Total no of cases with major } \\
\text { complications }\end{array}$ & 8 & 5 \\
\hline Minor & & \\
\hline Fever & 10 & 6.25 \\
\hline Urinary tract infection & 9 & 5.62 \\
\hline Port site infection & 3 & 1.87 \\
\hline Vaginal vault abscess & 3 & 1.87 \\
\hline Paralytic ileus & 2 & 1.25 \\
\hline $\begin{array}{l}\text { Total no of cases with minor } \\
\text { complications }\end{array}$ & 27 & 16.87 \\
\hline
\end{tabular}


Only one case of ureteric injury noted. One case of bowel injury was seen, occur due to use of scissor during adhesiolysis, which was repaired primarily. Among minor complications fever $(6.25 \%)$ and urinary tract infection $(5.62 \%)$ were mainly seen.

Table 8 shows that $73.75 \%$ patients discharge within $2-4$ days. Mean duration of hospital stay was $2.82 \pm 1.17$ days.

Table 8: Duration of hospital stay.

\begin{tabular}{|lll|}
\hline Duration of hospital stay & $\begin{array}{l}\text { No. of cases } \\
(\mathbf{N}=160)\end{array}$ & $\%$ \\
\hline$<2$ days & 31 & 19.37 \\
\hline $\mathbf{2 - 4}$ days & 118 & 73.75 \\
\hline 4- 8 days & 11 & 6.87 \\
\hline Mean duration of stay & $2.82 \pm 1.17$ days \\
\hline
\end{tabular}

\section{DISCUSSION}

Mean age of patients in this study was 40-50 year. Majority women were parous. A critical factor in considering the degree of difficulty of a laparoscopic operation is the number of previous surgeries the patient has had. Previous surgeries cause adhesions, and adhesions can make the next operation much more difficult. Severe adhesion cases can be so long and time consuming that the surgeon makes no progress and converts to a laparotomy. ${ }^{7}$ In this study, although majority of women had not undergone any surgery in the past, there were 49 women with previous 1 LSCS, 16 women with previous 2 LSCS and 8 cases with more than 2 previous LSCS.

Majority of study group cases had uterine size 6-12 weeks. Most common indication of hysterectomy in this study was fibroid uterus $(49.37 \%)$ followed by dysfunctional uterine bleeding $(16.87 \%)$. All specimen was sent as a routine for pathological examination. The most common finding was myoma. According to Kapoor Nisha et al in their study, commonest indication of hysterectomy was fibroid $(44.9 \%) .{ }^{8}$ Ramesh et al reported fibroid $(54.4 \%)$ to be the most common cause of hysterectomy. ${ }^{9}$ The concomitant surgical procedures that were done with this LAVHs didn't prolong the operative time except in cases of vaginal repair. The same was noticed by other surgeon. ${ }^{10,11}$ Most of the patients accepted concomitant surgery more readily with LAVH as compared to open surgery due to cosmetic reasons.

\section{Operation time and blood loss}

The duration of surgery was calculated from the first surgical incision to the time when the last skin suture was applied. The average operative time in this study was 114 min. Meikle et al in their study mentioned average operative time was 115 min. ${ }^{12}$ In another study by Sadik et al the average operating time was 118 min. ${ }^{13}$ Both studies results are comparable to this study. Actually, the duration of surgery depends on the expertise of the surgeon, better illumination sources and also on the vessel sealing device. The operative time is also affected by adhesions, increased uterine size and obesity. ${ }^{14}$ In this study average blood loss as determined by the anesthesiologists was $135 \mathrm{ml}$ which is similar to result reported by Johns et al in their study. ${ }^{10}$ Kapoor Nisha et al reported blood loss around $116 \mathrm{ml}$ which was lesser than this study. ${ }^{8}$ The blood loss was calculated accurately by subtracting the volume of irrigation fluid from the amount of fluid collected in suction apparatus. Usually the blood loss in LAVH is less as in laparoscopy the vision is magnified and the skin incision length is very small. The bleeding also very much dependent on the coagulation device used.

The mean weight of removed uterus as estimated by pathologist was $243 \mathrm{gm}$.

\section{Complications}

The intraoperative major complication rate of in this study was $5 \%$ which is significantly lower than $8.6 \%$ reported by one study and $22 \%$ reported by another study. ${ }^{15,16}$ Among major complications, bladder injury occurs in two cases $(1.25 \%)$ of previous LSCS. In one case there was thermal injury to urinary bladder following use of electro-cautery. Another case of bladder perforation due to thick dense adhesions to the lower uterine segment after two previous caesarean sections. It was easily repaired during the vaginal part of the procedure. Bladder injury is the most common complication of LAVH. The incidence of bladder complications occurring in $\mathrm{LAVH}$ is quite higher than other surgical methods such as open hysterectomy or vaginal hysterectomy i.e., $0.02 \%$ and $8.3 \% .{ }^{17}$

Thermal ureteric injury occurs in one patient $(0.62 \%)$ and was detected 10 days after surgery when the patient presented with left renal pain and hydronephrosis. This was managed by DJ stenting of left ureter for three months. Ureteral injury complication is reported to have a low incidence in $\mathrm{LAVH}$, ranging from $0 \%$ to $2 \% .^{18}$

Major haemorrhage were seen in two cases $(1.25 \%)$. Two cases $(1.25 \%)$ were converted to laparotomy procedure due to massive bleeding from the uterine artery, in one case, and in another case there was dense adhesion with bowel. One case of bowel injury was seen, occur due to use of scissor during adhesiolysis, which was repaired primarily.

Among postoperative minor complications fever (6.25\%) and urinary tract infection $(5.62 \%)$ were mainly seen. Port site infection seen in 3 cases $(1.87 \%)$, vaginal vault abscess seen in 3 cases $(1.87 \%)$, paralytic ileus seen in 2 cases $(1.25 \%)$.

Mean duration of hospital stay was $2.82 \pm 1.17$ days which is almost similar to study done by Nanavati et al. ${ }^{19}$ Other 
authors have reported hospital stay varying from 23 hours to 2.5 days.

The limitation of this study is that in this study the operations were done by different surgeon with different level of expertise and authors have not taken the postoperative pain evaluation. Post-operative pain evaluation could not be done as this was a retrospective study and pain scoring was not done in none of the cases.

\section{CONCLUSION}

LAVH enables the surgeon to convert most of the abdominal hysterectomies into vaginal ones and hence decreases postoperative pain, lower incidence of overall complications compared to open hysterectomy, lesser duration of hospital stays and rapid return to normal activity. It is also feasible and safe procedure in patients with large uterine size, fixation of the uterus by adhesions, previous pelvic surgery and adnexal pathology. Higher costs and learning curve are the major constraints at present, which in future hopefully would be taken care of, as has happened in other laparoscopic procedures.

\section{ACKNOWLEDGMENTS}

Authors would like to thank Fortis Escorts Hospital and Research Centre for the permission to conduct and publish of this study.

\section{Funding: No funding sources}

Conflict of interest: None declared

Ethical approval: Not required

\section{REFERENCES}

1. Whiteman MK, Hillis SD, Jamieson DJ, Morrow B, Podgornik MN, Brett KM, et al. Inpatient hysterectomy surveillance in the United States, 20002004. Am J Obstet Gynecol. 2008;198:1-7.

2. Kumar GS, Lekkala S. Complications after a total laparoscopic hysterectomy: a study in tertiary care unit in Telangana, India. Int Surg J. 2016;3(3):11415.

3. Reich H, Dicaprio J, McGlynn F. Laparoscopic hysterectomy. J Gynecol Surg. 1989;5:213-6.

4. Falcone T, Marie Fidele R. Paraiso, Marscha E. Prospective randomized clinical trial of laparoscopically assisted vaginal hysterectomy versus total abdominal hysterectomy. Am J Obstet Gynecol. 1999;180:955-62.

5. Wood C, Maher P, Hill D. Replacement of abdominal hysterectomy by the laparovaginal technique-its success and limitations. Aust N Z J Obstet Gynaecol. 1994;34:571-4.

6. Jones HW, Wentz AC, Burnet LS. Novak's Textbook of Gynecology. $11^{\text {th }}$ edition. Baltimore, Williams and Williams; 1988:29-31.

7. Reich H. Total laparoscopic hysterectomy: indications, techniques and outcomes. Curr Opin Obstet Gynecol. 2007;19(4):337-44.

8. Kapoor N, Manuja S, Mittal A. Laparoscopic assisted vaginal hysterectomy: an effective alternative to conventional abdominal hysterectomy. J Obstet Gynecol India. 2010;60(5):429-35.

9. Bettaiah R, Reddy CAR. Laparoscopic hysterectomies: our 10 years' experience in a single laparoscopic centre. The J Obstet Gynaecol India. 2016;66(4):274-81.

10. Johns DA, Diamond MP. Laparoscopically assisted vaginal hysterectomy. J Reprod Med. 1994;39:4248.

11. Hur M, Kim JH, Moon JS, Lee JC, Seo DW. Laparoscopically assisted vaginal hysterectomy. J Reprod Med. 1995;40:829-33.

12. Meikle SF, Nugent EW, Orleans M. Complications and recovery from laparoscopy-assisted vaginal hysterectomy compared with abdominal and vaginal hysterectomy. Obstet Gynecol. 1997;89:304-11.

13. Sadik S, Uran B, Ozaydin T. Laparoscopically assisted vaginal hysterectomy and bilateral salpingoophrectomy with suturing technique. J Am Ass Gynecol Lap. 1995;5:437-40.

14. Chang WC, Lin WC, Hung YC. Pelvic adhesions and laparoscopic assisted vaginal hysterectomy. Int $\mathbf{J}$ Gynaecol Obstet. 2006;94:145-6.

15. Pelosi MA, Kader N. Laparoscopically assisted vaginal hysterectomy for uteri weighing $500 \mathrm{gm}$ or more. J Am Assoc Gynecol Laparosc. 1994;1:405-9.

16. Bornstein SJ, Shaber RE. Laparoscopically assisted vaginal hysterectomy at a health maintenance organization. Cost effectiveness and comparison with total abdominal hysterectomy. J Repord Med. 1995;40:435-8.

17. Ostrzenski A, Ostrzenska KM. Bladder injury during laparoscopic surgery. Obstet Gynecol Surv. 1998;53:175-80.

18. Ostrzenski A, Radolinski B, Ostrzenska KM. A review of laparoscopic ureteral injury in pelvic surgery. Obstet Gynecol Surv. 2003;58:794-9.

19. Nanavati AM, Gokral SB. A prospective randomised comparative study of vaginal, abdominal, and laparoscopic hysterectomies. The J Obstet Gynaecol India. 2016;66(S1):S389-S394.

Cite this article as: Rajput N, Yadav SS, Narwade P. Laparoscopic assisted vaginal hysterectomy: an experience at a Fortis Escorts hospital. Int J Reprod Contracept Obstet Gynecol 2020;9:3749-53. 